\title{
Konlk KAJIAN ESTETIKA KUPIAH RIMAN DESA DAYAH Jurnal seni dan Desain ADAN KABUPATEN PIDIE
}

Volume 3, Nomor 1 Januari 2021

$(23-27)$

\author{
Fauziana Izzati ${ }^{1}$, Putri Dahlia ${ }^{2}$, Tria Ocktarizka ${ }^{3}$ \\ Institut Seni Budaya Indonesia Aceh, Indonesia \\ e-mail: fauzianaizzati@gmail.com ${ }^{1}$,putrydahlia0101@gmail.com ${ }^{2}$ \\ triaocktarizka93@gmail.com ${ }^{3}$
}

\begin{abstract}
ABSTRAK
Daerah Aceh kaya akan kebudayaan, banyak hasil kebudayaan Aceh yang tidak terlepas dari nuansa Islami, salah satu contoh dalam seni rupa adalah kupiah riman yang digunakan oleh kaum lelaki Aceh. Sampai saat ini kerajinan kupiah riman masih diproduksi di Desa Dayah Adan Kecamatan Mutiara Timur Kabupaten Pidie. Kupiah riman memiliki ciri khas motif tradisional Aceh, seperti: motif pintoe Aceh, bungong kupula, bungong jeumpa,dan lain-lain. Pengetahuan tentang bentuk dan nilai keindahan/ estetika yang terkandung di dalam kupiah riman tidak diketahui oleh sebagian besar masyarakat Aceh saat ini. Masyarakat Aceh menganggap motif tersebut hanya sebagai hiasan semata. Nilai keindahan tersebut menarik untuk diteliti karena kupiah riman memiliki dua bentuk yaitu lonjong dan bulat. Kupiah ini digunakan dalam berbagai upacara adat. Penelitian ini bertujuan agar masyarakat Aceh pada umunya dan Kabupaten Pidie khususnya dapat mengenal kekayaan budaya daerah seperti kupiah riman agar dapat dijaga dan dilestarikan keberadaannya.Penelitian ini akan menggunakan teori estetika Monroe yaitu kesatuan (unity), kerumitan (complexity), dan kesungguhan (intensity) untuk menganalisis kupiah riman. Hasil penelitian ini nantinya dapat dijadikan sebagai acuan atau referensi bagi penelitian selanjutnya mengenai kupiah riman. Hal ini juga berpengaruh terhadap industri kerajinan kupiah riman yang ada di Desa Dayah Adan karena diharapkan melalui penelitian ini produk kupiah riman semakin dikenal.
\end{abstract}

Kata Kunci: Estetika ,Kupiah Riman, Ornamen

\section{ABSTRACT}

Aceh is rich of culture, many of its culture has islamic nuances, one of the example in art is "kupiah riman" which is used by man in aceh. Until now the handicraft of "kupiah riman" is still produced in Dayah village, Mutiara Timur sub district, district of pidie. Kupiah riman has characteristic traditional design of aceh, like : pintoe aceh design, bungong kupula design, bungong jeumpa design, etc. Nowadays, The knowledge about form and estetic value in kupiah riman is unknown by most of native people in aceh.people in aceh assumed that the design only as handicraft. The estetic value are interesting to be researched because kupiah riman has 2 form, there are oval and circle. This kupiah is used in many of traditional ceremonies. This research is aimed to purpose the people in aceh in general, and especially pidei distric know the wealth of region culture like kupiah timan, so that it can be saved and preserved. This research will use monroe estetic theory (unity), complexity, and intensity to analize kupiah ruman. The result of the research furthermore can be references to the next research. It also has influence to the handicraft industry sector of kupiah riman in dayah village, the researcher hope, due to this research, kupiah riman is more knowable.

Key Words: Kupiah Riman, Ornament, Aesthetic

\section{PENDAHULUAN}

Gresik merupakan salah satu kabupaten di Aceh merupakan provinsi yang terletak di ujung utara pulau Sumatera dan merupakan provinsi paling barat di Indonesia. Daerah Aceh kaya akan kebudayaan dan masih menjunjung tinggi nilai-nilai sejarah, mulai dari bahasa yang digunakan, pakaian adat, tari-tarian, rumah adat, makanan tradisional, senjata tradisional dan lain-lain. Banyak hasil kebudayaan Aceh yang tidak terlepas dari nuansa Islami, salah satu contoh dalam seni rupa adalah kerajinan tradisional dalam bentuk kupiah. Menurut Poerwadarminta, kupiah/peci adalah 
sejenis topi berbentuk pendek yang dikenakan di kepala oleh kaum laki-laki (2006: 38). Aceh memiliki berbagai macam bentuk kupiah. Hossein Djadiningrat menyebutkan berbagai macam kupiah laki-laki Aceh antara lain: kupiah Aceh, kupiah teureuboih (peci Turki) atau kupiah mirah (peci merah), kupiah puteh (peci putih), kupiah punci, kupiah meukeutob, kupiah aleupi, kupiah apui (peci api), kupiah ija thjam, kupiah Arab, kupiah bludu (peci beludru), kupiah kleng (peci hitam), kupiah teulasoen dan kupiah riman (Rasyid, 2008: 12).Kupiah riman berasal dari Kabupaten Pidie. Sampai saat ini di daerah tersebut masih memproduksi kerajinan kupiah riman yang berada di Desa Dayah Adan Kecamatan Mutiara Timur Kabupaten Pidie. Dinamakan kupiah riman karena pada awalnya merupakan nama sebuah pohon yang dijadikan bahan pembuatan kupiah riman tersebut, seiiring berjalannya waktu pohon riman tersebut mulai langka dan kemudian diganti dengan serat pohon aren. Kupiah riman memiliki ciri khas motif. Motif yang terdapat pada kupiah riman diantaranya: motif pintoe (pintu) Aceh, bungong kupula (bunga tanjung), bungong jeumpa (bunga cempaka), gareh peulangi (garis pelangi), pucok reubong (pucuk rebung), mutiara, bintang, petak (persegi), awan, taloe ie (tali air), bata meususon (bata tersusun), dan pucok meuriya (pucuk rumbia).

Kupiah riman memiliki dua bentuk yaitu lonjong dan bulat. Meskipun bentuk kupiah ini sederhana, namun diperlukan keahlian khusus dan ketelatenan serta kesabaran dalam pembuatannya. Untuk merajut sebuah kupiah diperlukan waktu sekitar 15 hari (Rasyid: 2008: 21). Bahan baku pembuatan kupiah riman ini adalah serat pohon aren karena di daerah Pidie terdapat banyak pohon tersebut. Bahan pewarna yang digunakan juga masih menggunakan bahan alami seperti daun peuno dan lumpur. Kupiah riman dahulu hanya dipakai oleh kaum bangsawan laki-laki dalam berbagai upacara adat atau upacara resmi lainnya pada masa kepemimpinan Sultan Iskandar Muda. Saat ini kupiah riman digunakan oleh pejabat dan masyarakat biasa di daerah Aceh dalam berbagai acara resmi dan untuk

keperluan ibadah. Pengetahuan tentang bentuk dan nilai keindahan yang terkandung di dalam kupiah riman tidak diketahui oleh sebagian besar masyarakat Aceh saat ini. Masyarakat Aceh menganggap motif tersebut hanya sebagai hiasan semata. Dewasa ini masyarakat Pidie sudah jarang menggunakan kupiah riman dalam kehidupan sehari-hari karena harga kupiah riman yang tergolong mahal.

Berdasarkan latar belakang di atas, Tim peneliti dari Institut Seni Budaya Indonesia Aceh sebagai kampus seni yang akan mengangkat khazanah kebudayaan Aceh perlu melakukan penelitian mengenai nilai keindahan dari kupiah riman di Desa Dayah Adan Kecamatan Mutiara Timur Kabupaten Pidie. Nilai keindahan tersebut menarik untuk diteliti karena kupiah riman memiliki dua bentuk yaitu lonjong dan bulat. Kupiah tersebut juga dihiasi dengan berbagai macam motif tradisional Aceh serta kupiah ini digunakan laki-laki Aceh dalam berbagai upacara adat.

Penelitian ini bertujuan agar masyarakat Aceh pada umunya dan Kabupaten Pidie khususnya dapat mengenal kekayaan budaya daerah seperti kupiah riman agar dapat dijaga dan dilestarikan keberadaannya. Hasil penelitian ini nantinya dapat dijadikan sebagai acuan atau referensi bagi penelitian selanjutnya mengenai kupiah riman. Hal ini juga berpengaruh terhadap industri kerajinan kupiah riman yang ada di Desa Dayah Adan Kecamatan Mutiara Timur Kabupaten Pidie karena diharapkan melalui penelitian ini produk kupiah riman semakin dikenal..

\section{METODE PENELITIAN}

Penelitian ini menggunakan metode kualitatif dengan jenis pendekatan deskriptif. Metode penelitian kualitatif merupakan teknik pengumpulan data yang dilakukan secara gabungan, analisis data bersifat induktif dan penelitian kualitatif lebih menekankan kepada makna daripada generalisasi (Sugiyono, 2014:9), sedangkan jenis penelitian deskriptif merupakan penelitian yang berusaha menggambarkan atau menginterpretasikan objek sesuai dengan apa adanya (Nazir, 2009:55). Pada penelitian ini, peneliti dalam mendapatkan data-data telah melakukan antara lain membina hubungan baik dengan informan penelitian sehingga tercipta suasana yang santai dan wajar dengan informan tetapi dengan tetap menjalankan protokol kesehatan.

Dalam pengumpulan data, peneliti memulai penelitian dengan melakukan pengamatan atau observasi. Observasi merupakan suatu proses pengamatan dan ingatan (Sugiyono, 2014:145). Peneliti mengamati secara langsung ke lokasi penelitian yaitu ke desa Dayah Adan, kecamatan Mutiara Timur Kabupaten Pidie. Penelitian ini juga melakukan wawancara sebagai dasar untuk memperoleh informasi terkait objek penelitian. Peneliti menggunakan handphone sebagai alat perekam untuk mendokumentasikan hasil wawancara antara peneliti dan informan. Informan yang diwawancarai diantaranya adalah ketua kelompok perajin kupiah riman dan perajin kupiah riman. Hasil dokumentasi yang dilakukan oleh peneliti dengan mengumpulkan beberapa tulisantulisan, dan mengambil beberapa foto-foto yang memperlihatkan kupiah riman secara jelas. Peneliti menggunakan kamera untuk mendokumentasi 
objek penelitian agar dapat menjadi data tambahan yang berhubungan dengan penelitian ini.

\section{HASIL DAN PEMBAHASAN}

\section{Awal Mula Kupiah Riman}

Pembuatan kupiah khas Aceh warisan Sultan Iskandar Muda ini dihidupkan kembali sejak tahun 1985 silam. Awalnya, kerajinan ini hanya untuk memenuhi kebutuhan pribadi. Namun, karena peminatnya semakin banyak, pembuatan kopiah ini kemudian menjadi usaha sampingan yang dapat menghasilkan uang. Menurut Badriyah di tahun 1985, Dinas Perindustrian dan Perdagangan Aceh mencari informasi kerajinankerajinan yang ada di Kabupaten Pidie, sehingga terpilihlah kerajinan Desa Dayah Adan karena adanya kupiah riman tersebut yang dianggap unik dan mempunyai peluang usaha serta untuk melestarikan daerah setempat.

Disebut kupiah riman karena dahulu kupiah ini dibuat dari serat pohon riman. Namun saat ini keberadaan pohon tersebut sudah sangat langka. Oleh karena itu bahan utama pembuatan kupiah riman diganti dengan serat pohon aren, seratnya hampir sama dengan serat pohon riman. Meski menggunakan serat pohon aren, penamaan kupiah ini tetap disebut kupiah riman karena kupiah ini merupakan kupiah tradisional yang penamaannya sudah melekat pada masyarakat aceh terutama Kabupaten Pidie.

\section{Bentuk Kupiah Riman}

Kupiah riman terdiri dari 2 lapisan, yaitu lapisan dalam dan lapisan luar. Lapisan dalam berfungsi sebagai alas bagian dalam agar pengguna nyaman memakainya. Serat lapisan luar ini cenderung lebih kasar dibandingkan dengan serat bagian luar. Pada lapisan luar terdapat motif sebagai penghias. Bentuk kupiah riman tidak jauh berbeda dengan bentuk kupiah yang biasanya digunakan kaum laki-laki dalam melaksanakan ibadah shalat. Kupiah riman terdiri dari 2 bentuk, yaitu bentuk bulat dan bentuk lonjong.

\section{a. Bentuk Bulat}

Kupiah riman dengan bentuk bulat dibuat mengikuti bentuk bulat kepala. Motif yang biasanya digunakan pada kupiah riman bentuk bulat seperti: motif pucok reubong, bata meususon, bungong jeumpa, bungong kemula, motif taloe ie (likok), dan motif gareuh peulangi. Kupiah riman dengan bentuk bulat ini merupakan bentuk pertama yang dibuat dan masih diproduksi hingga saat ini. Pada saat sekarang pembuatan kupiah riman yang bulat ini sudah disesuaikan dengan kreatifitas masingmasing perajin melalui penerapan motif tradisional dan motif kreasi tanpa meninggalkan ciri khas dari kupiah riman itu sendiri. Berikut salah satu contoh kupiah riman berbentuk bulat:

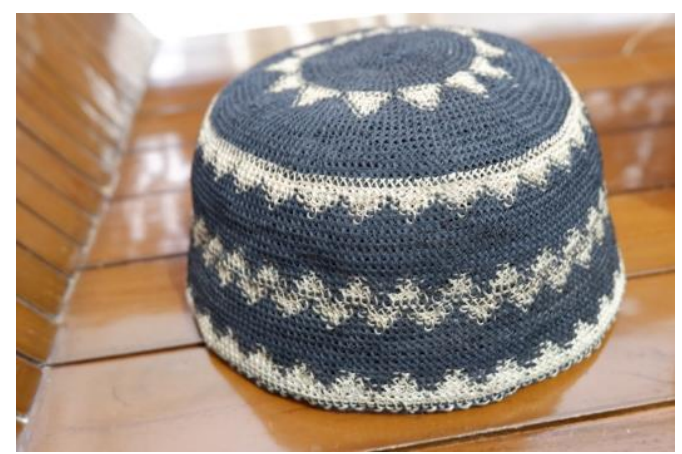

Gambar 1

Kupiah Riman Bentuk Bulat

Foto : Tria Ocktarizka, 2020

Kupiah pada gambar di atas terdiri dari dua motif, yaitu motif pucoek reubong diposisikan pada bagian puncak atas kupiah, pinggir atas dan bagian pinggir bawah kupiah, dan di bagian tengah kupiah terdapat motif taloe ie.

\section{b. Bentuk Lonjong}

Kupiah riman dengan bentuk lonjong merupakan bentuk lain dari kupiah riman selain bentuk bulat. Pada umumnya motif yang diterapkan pada kupiah riman bentuk lonjong sama dengan motif yang diterapkan pada kupiah bentuk bulat dan juga disesuaikan dengan kreatifitas masing-masing perajin melalui penerapan motif tradisional dan motif kreasi tanpa meninggalkan ciri khas dari kupiah riman itu sendiri. Berikut salah satu contoh kupiah riman berbentuk lonjong:

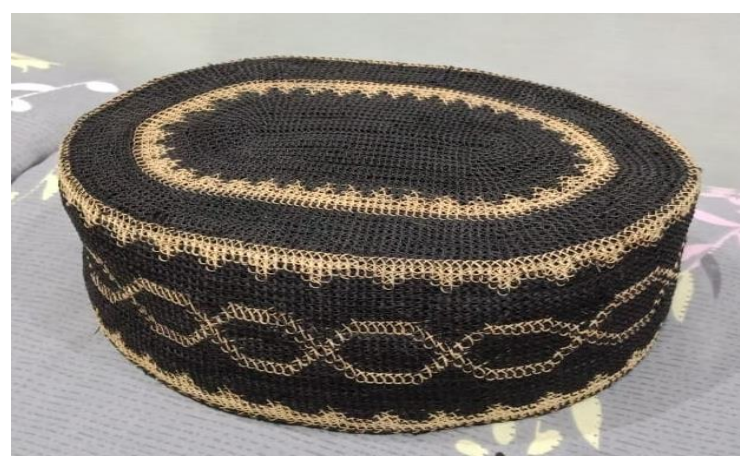

Gambar 2

Kupiah Riman Bentuk Lonjong

Foto : Tria Ocktarizka, 2020 
Motif yang digunakan pada kupiah riman di atas adalah motif tradisional pucoek reubong dan motif kreasi perajin yaitu motif silet. Motif pucoek reubong diposisikan pada bagian puncak kupiah, bentuknya dibuat secara melingkar mengikuti bentuk kupiah. Selain itu motif pucoek reubong juga diposisikan pada bagian pinggir atas kupiah. Bagian tengah kupiah terdapat motif silet, yaitu motif kreasi yang diciptakan perajin. Motif kreasi diciptakan perajin terinspirasi melalui pengamatan benda-benda yang ada di sekitar lingkungan mereka.

\section{Estetika Kupiah Riman}

Monroe Beardsley dalam Problems In the Philosophy of Criticism yang menjelaskan adanya 3 ciri yang menjadi sifat-sifat membuat baik (indah) dari benda-benda estetis pada umumnya. Ketiga ciri termasuk ialah:

1. Kesatuan (Unity), ini berarti bahwa benda estetis ini tersusun secara baik atau sempurna bentuknya. Kesatuan pada suatu karya seni memerlukan prinsip keseimbangan, irama, proporsi, dan keselarasan. Dalam penerapannya pada benda kriya atau seni rupa kesatuan menekankan pada pengaturan objek secara berdekatan atau penggerombolan unsur atau pada bagian tertentu. Selain itu juga dapat dapat dilihat dari unsur-unsur seni rupa (garis, tekstur, warna, bidang, dan lain-lain) yang bekerja sama dalam menciptakann keteraturan sehingga menjadi suatu kesatuan dari karya tersebut. Pada Kupiah Riman kesatuan dapat dilihat dari repetisi beberapa motif yang diterapkan pada beberapa bagian kupiah secara sistematis. Repetisi penempatan motif-motif pada kupiah riman diantaranya pada bagian pinggir, bagian tengah dan bagian atas kupiah yang mengikuti bentuk pola kupiah sehingga menghasilkan suatu bentuk kesatuaan yang utuh.

2. Kerumitan (complexity), benda estetis atau karya seni yang bersangkutan tidak sederhana sekali, melainkan kaya akan isi maupun unsurunsur yang berlawanan atau mengandung perbedaan yang halus antara satu dengan karya yang lainnya. Kupiah riman dari segi bentuk memang terlihat sederhana, akan tetapi kupiah riman memiliki nilai filosofis yang terdapat pada motif motifnya. Pada kupiah riman terdapat beberapa jenis motif yang memilki nilai dan makna yang berhubungan dengan kehidupan masyarakat salah satunya motif Pucok Reubong.
Motif Pucok Reubong merupakan motif yang bentuknya distilisasi dari bentuk pucuk rebung. Motif ini mempunyai makna yaitu melambangkan adat istiadat dalam Masyarakat Aceh. Selain motif Pucuk Reubong, terdapat juga motif Bungong Jeumpa yang dijadikan simbol keindahan dan juga mempunyai makna keharuman. Motif Bungong Jeumpa merupakan sebuah filosofis atas penghargaan masyarakat kepada generasi-generasi yang ada di Aceh dalam mengharumkan nama Aceh (Ismawan, 2018:226-231). Selain dua motif di atas masih ada beberapa motif yang terdapat pada kupiah riman seperti motif bata meususon, motif awan meucanek, motif bintang, motif mata silet, motif pintoe aceh yang semuanya memiliki nilai dan makna ditengah kehidupan masyarakat aceh khususnya daerah Pidie.

3. Kesunggguhan (intensity), suatu benda estetis yang baik harus mempunyai suatu kualitas tertentu yang menonjol dan bukan sekedar sesuatu yang kosong. Tak menjadi soal kualitas apa yang dikandungnya misalkan suasana suran atau gembira, sifat lembut atau kasar), asalkan merupakan sesuatu yang intensif atau sungguhsungguh. Kesungguhan dapat dilihat dari teknik pembuatan yang memerlukan waktu yang lama sekitar satu bulan. Proses pembuatan kupiah riman dimulai dari mengolah pelepah pohon manjadi serat serat yang halus, selanjutnya serat tersebut diberi warna dengan getah "oen peuno" (daun peuno) yang dicampurkan dengan lumpur Setelah benang selesai diberi warna, maka proses selanjutnya adalah pembuatan kupiah riman memakai teknik rajut. Kesungguhan dalam proses merajut juga memberikan kesan halus dan rapi pada kupiah ,semakin halus serat yang digunakan maka akan semakin rapat dan akan semakin mahal harga dari kupiah rima tersebut.

\section{KESIMPULAN}

Kupiah riman merupakan penutup kepala laki-laki Aceh yang berasal dari Kabupaten Pidie yaitu di Desa Dayah Adan Kecamatan Mutiara. Kupiah riman terdiri dari 2 bentuk, yaitu bentuk lonjong dan bentuk bulat. Pada kupiah terdapat berbagai motif tradisional Aceh maupun motif kreasi yang dihasilkan oleh perajin. Motif tradisional yang digunakan seperti motif pintoe Aceh, bungong kupula, bungong jeumpa, pucok reubong dan lain-lain. Sedangkan motif kreasi yang diciptakan oleh perajin merujuk kepada pengamatan terhadap benda-benda sekitar seperti 
motif petak, silet, motif bintang, motif pelangi, dan lain-lain.

Keindahan kupiah riman dalam penelitian ini dapat dilihat dari 3 ciri-ciri keindahan menurut Monroe Beardsley, yaitu adanya kesatuan / unity yang memuat tentang prinsip keseimbangan, irama, proporsi, dan keselarasan. Selanjutnya adalah adanya kerumitan / complexity, dalam artian karya tersebut tidak terlalu sederhana. Terakhir adalah adanya kesungguhan / intensity, yang dapat dilihat dari lamanya proses pembuatan sebuah karya.

Keindahan baik dari segi bentuk dan motif yang terdapat pada kupiah riman tidak banyak diketahui oleh masyarakat Aceh pada saat ini. Masyarakat hanya memandang bahwa kupiah riman digunakan oleh kaum laki-laki aceh sebagai penghias kepala dan untuk keperluan ibadah dan acara penting lainnya. Padahal pada kenyataannya terdapat nilai estetika yang sangat mendalam pada kupiah tersebut.

Penelitian mengenai estetika kupiah riman merupakan upaya yang dapat dilakukan agar masyarakat ke depannya mengetahui dan lebih menghargai serta mempertahankan peninggalan produk budaya secara turun temurun ini yang masih dapat ditemui di daerah Desa Dayah Adan. Masih banyak terdapat para perajin di daerah ini yang masih memproduksi kerajinan kupiah riman. Penulis juga mengharapkan agar perajin dapat meningkatkan kemampuan menciptakan dan mengutamakan kualitas produk kupiah riman dan tetap menggunakan bahan alami dalam pembuatan kupiah riman.

Harapan selanjutnya adalah agar pemerintah Kabupaten Pidie dapat memfasilitasi sarana yang dapat menghubungkan perajin kupiah riman dengan konsumen yang lebih luas. Perlu ditingkatkan kualitas perajin dengan membina secara teratur dan terukur sehingga mampu menciptakan desain motif kreasi terbaru. Bagi insan akademis semoga hasil penelitian ini dapat dijadikan sebagai referensi dalam melalakukan penelitian selanjutnya tentang kupiah riman.

Penulis menyadari terdapat banyak kekurangan dalam penelitian mengenai "Kajian Estetika Kupiah Riman Di Desa Adan Kabupaten
Pidie", untuk itu penulis mengharapkan adanya saran, kritikan dan masukan yang membangun demi tercapainya penulisan yang lebih baik untuk ke depannya.

\section{DAFTAR PUSTAKA}

Endraswara, Suwardi.2012. Metode Penelitian Kebudayaan. Jogyakarta: Universitas Gadjah Mada.

Ernawati, E. (2019). Kosmologi sebagai Pijakan Kreasi dalam Berkarya Seni (Cosmology as the Foundation of Creation in Artwork). INVENSI (Jurnal Penciptaan Dan Pengkajian Seni), 4(2), 113-129.

Kumsatun. 2002. Ragam Hias dan Motif Aceh. Provinsi Nanggroe Aceh Darussalam: Dekranas.

Ismawan, dkk. 2017. "Pola Komposisi Motif Kupiah Riman di Desa Adan Meunasah Dayah Kecamatan Mutiara Timur Kabupaten Pidie". Jurnal Seni Budaya. Volume IV, Nomor 1: 30 48. Banda Aceh: Unsyiah.

2018. "Ragam Motif dan Makna yang Terdapat pada Kupiah Riman di Desa Adan Meunasah Dayah Kecamatan Mutiara Kabupaten Pidie". Jurnal Ilmiah Mahasiswa Program Studi Pendidikan Seni Drama, Tari dan Musik. Volume 111, Nomor 2: 224-233. Banda Aceh: Unsyiah.

Leumik, Harun Keuchik. 2016. Kemilau Warisan Budaya Aceh. Banda Aceh: Toko Mas Permata dan Sovenir H. Keuchik Leumiek.

Nazir, Moh. 2013. "Metode Penelitian". Bogor: Ghalia Indonesia

Nurmuttaqin, T Ikkin, dkk. 2016. "Motif Ragam Hias Kupiah Aceh". Jurnal Ilmiah Mahasiswa Program Studi Pendidikan Seni Drama, Tari dan Musik. Volume 1. Nomor 2 : 147-154. Banda Aceh: Unsyiah.

Rasyid, A Hamid. 2008. Penutup Kepala Laki-Laki Etnis Aceh. Provinsi Nanggroe Aceh Darussalam: Dinas Kebudayaan \& Pariwisata.

Sony Kartika, Dharsono. 2016. "Kreasi Artistik". Karanganyar: Citra Sains

Sony Kartika, Dharsono. 2007. "Estetika”] \. Bandung: Rekayasa Sains

Sugiyono. 2014. "Metode Penelitian Kuantitatif, Kualitatif, dan R\&D". Bandung: PT Alfabet 